\title{
Comparison of short and long axis T1 and ECV maps in patients with myocarditis
}

\author{
Sebastian Bohnen ${ }^{1 *}$, Ulf K Radunski ${ }^{1}$, Gunnar Lund ${ }^{3}$, Lena M Wilmink' ${ }^{1}$ Christian Stehning ${ }^{2}$, Gerhard Adam³, \\ Stefan Blankenberg ${ }^{1}$, Kai Muellerleile ${ }^{1}$ \\ From 18th Annual SCMR Scientific Sessions \\ Nice, France. 4-7 February 2015
}

\section{Background}

T1 mapping and ECV imaging are promising diagnostic tools in patients with suspected myocarditis. However, there are currently no data on the potential influence of slice orientation on the derived $\mathrm{T} 1$ and ECV values. Thus, we compared global myocardial T1 and ECV values between slices with short and long axis orientation.

\section{Methods}

This study included 50 patients with clinically suspected myocarditis, who underwent CMR at 1.5 Tesla. T1 quantification was performed on three short (basis, center, apex) and on three long axis slices (2-, 3- and 4-chamber orientation), respectively. The modified Look-Locker inversionrecovery (MOLLI) sequence was used before and $15 \mathrm{~min}$ utes after administration of $0.075 \mathrm{mmol} / \mathrm{kg}$ GadoliniumBOPTA. Native T1, post-contrast T1 and extracellular volume (ECV) maps were calculated using a dedicated plug-in written for the OsiriX software. Mean native and post-contrast T1 as well as ECV were obtained from the three short and long axes, respectively.

\section{Results}

There were significantly lower median native myocardial T1 values on long axis slices (1079 (1040-1130.0)) compared to short axis slices (1103 (1069-1140); $\mathrm{p}=0.0026)$. However, there were no significant differences in postcontrast myocardial T1 values (median 554 (505-596) vs. 555 (509-601); $\mathrm{p}=0.2299$ ) or ECV (median 30 (27-33) vs. 29 (26-33); $\mathrm{p}=0.6063)$ between short and long axis slices, respectively.

\section{Conclusions}

Slice orientation could be a potential confounding factor for the assessment of native global myocardial T1 values in myocarditis. Possible explanations for this finding include technical issues, such as variations in throughplane motion or partial-volume effects related to slice orientation, but also the heterogeneity of myocardial injury in myocarditis. However, our data indicate that global myocardial ECV values could be less sensitive to slice orientation.

\section{Authors' details}

${ }^{1}$ Cardiology, University Heart Center, Hamburg, Germany. ${ }^{2}$ Philips Research Europe, Hamburg, Germany. ${ }^{3}$ Diagnostic and Interventional Radiology, University Hospital Hamburg Eppendorf, Hamburg, Germany.

Published: 3 February 2015

doi:10.1186/1532-429X-17-S1-P265

Cite this article as: Bohnen et al:: Comparison of short and long axis T1 and ECV maps in patients with myocarditis. Journal of Cardiovascular Magnetic Resonance 2015 17(Suppl 1):P265.

Submit your next manuscript to BioMed Central and take full advantage of:

- Convenient online submission

- Thorough peer review

- No space constraints or color figure charges

- Immediate publication on acceptance

- Inclusion in PubMed, CAS, Scopus and Google Scholar

- Research which is freely available for redistribution 